\title{
Applying RAMSSHEEP analysis for risk-driven maintenance
}

\author{
W. Wagner \\ DPI Consultancy, Haarlem, The Netherlands \\ P.H.A.J.M. van Gelder \\ TU-Delft, Delft, The Netherlands
}

\begin{abstract}
The Ministry of Infrastructure and the Environment of The Netherlands and Rijkswaterstaat (RWS) aim to launch a risk-driven maintenance concept named RAMSSHEEP. Engineering and consultancy companies are expected to develop the RAMSSHEEP concept in order to create better maintenance strategies. The objective is to investigate whether RAMSSHEEP can be applied as a risk-driven maintenance tool for primary flood defence systems in The Netherlands. By applying a probabilistic approach to a flooding problem, more insight is gained in the advantages and disadvantages of RAMSSHEEP. This paper addresses the problem which primary flood defence systems experience with respect to maintenance strategies. Often external political pressure is applied to improve reliability and availability and to reduce costs significantly. Therefore this paper suggests an approach that is able to find an optimal maintenance strategy by finding the economic most beneficial maintenance interval.
\end{abstract}

\section{INTRODUCTION}

The Ministry of Infrastructure and the Environment and Rijkswaterstaat (RWS) aim to launch a certain risk-driven maintenance concept named RAMSSHEEP (Reliability, Availability, Maintainability, Safety, Security, Health, Environment, Economics and Politics) that will be further developed by engineering and consultancy companies. The objective of this research is to assess whether RAMSSHEEP can be applied as a risk-driven maintenance tool, based on the results of the existing method of a probabilistic approach with 'Life Cycle Costs' (LCC). By applying a probabilistic approach more insight is gained in the advantages and disadvantages of RAMSSHEEP.

\section{$1.1 \quad R A M S$}

Nowadays the world exists of complex installations and processes. These installations and processes are expected to be reliable and become more important due to the high-technical mechanization systems (Moubray 1997). The installations and processes in society will be indicated as reliable and robust until system failure occurs. Questions arise, like:

- What is the reason for system failure?;

- Who or what is responsible?; and

- How to prevent system failure from happening again?
More and more (large) companies have made an inventory of their process system(s) and qualified and quantified the possible risks that may endanger an optimal reliable performance of the system. The main purpose is based on controlling or even avoiding risks during operating phase (Andrews \& Moss 2002). Therefore maintaining a system will play a crucial role in ensuring the reliability and availability of the system is as high as possible against the lowest possible costs (optimization of efficiency). So by applying the concept of risk management it is possible to get an indication of the reliability of the system and how actions can be taken to ensure an optimal condition of the system (Zaal 2011).

A well-known analysis to get an indication of the performance reliability (quality) of the functioning of a system can be described by Reliability, Availability, Maintainability and Safety (RAMS). The RAMS analysis can be seen as a risk concept that describes the primary performance of all the functions of a system. A RAMS analysis can be used in every stage of the life cycle for the entire infrastructure in The Netherlands: road network, major waterways and main waters. This analysis can be applied on a complete system but also for small components within a network. Crucial information for a management team is:

- Is the system available?;

- Do the objects fulfill its purpose (function)?;

- What is the condition of the objects?; 
- Is the system safe to use and to maintain?; and

- When and how is maintenance applied to the system?

These questions will be made comprehensible by executing a RAMS analysis: consistency of Reliability, Availability, Maintainability and Safety. The RAMS analysis is an unambiguous method to estimate the risks of a system and it may result in several measures that must be taken to fulfill the system to its requirements. Therefore many users can apply this analysis in the system, i.e. the client, contractor, and etc.

\subsection{History and background}

In the seventies of last century the American Defense industry in corporation with the civil aircraft industry developed a Reliability-Centered Maintenance (RCM) approach whereby reliability played a crucial role in the system (Moubray 1997). In the late seventies a risk method has been developed called Failure Mode and Effect Analysis (FMEA) to analyze the Reliability, Availability and Maintainability of a technical system. The official document 'Military Standard 1629a', which has been published in 1980, has been one of the most important sources for the RAMSSHEEP theory nowadays (Van Gestel et al. 2004).

In the late eighties the European Commission decided to divide the properties in the rail sector: the infrastructure was managed by the nation and the exploitation of the trains was managed by the private sector. This led directly to a response in the rail sector to create a method that considers the performance of a system and how this can be tested. Therefore the RAMS analysis has been used which has been developed in the US (Nowlan \& Heap 1978). Over the years this analysis has been expanded and further developed based on the technique in the major industrial sector. This method has been taken over by other infrastructural sectors (rail sector, civil engineering sector, and etc.). In the 00's the RAMS analysis has been expanded to more aspects that should be considered by the determination of the reliability of a system: the so-called RAMSSHEEP analysis. Developments in the risk concept of RAMS analysis lead to the expansion on more societal aspects.

\section{RAMSSHEEP ANALYSIS}

\subsection{Original definition}

By introducing RAMSSHEEP in several tenders the current market will be pushed to develop RAMSSHEEP further so the analysis can be taken to a higher level (Van den Breemer et al. 2009).
Before going into detail of the aspects, first the whole definition of RAMSSHEEP is given (Rijkswaterstaat 2012):

- Reliability-indicates the failure probability of a system in which its functions cannot be fulfilled.

- Availability -indicates the time duration in which the system is functional and its functions can be fulfilled.

- Maintainability - the ease in which the system can be maintained over time.

- Safety - the absence of human injuries during using or maintaining the system.

- Security - a safe system with respect to vandalism, terrorism and human errors.

- Health - the objective argument of good health with respect to the physical, mental and societal views.

- Environment-influence of the system on its direct physical environment.

- Economics - a serious reflection in terms of costs versus benefits (as well as direct and indirect) to provide more insight for an economical responsible choice.

- Politics - a rational decision on all the previous aspects.

It may be obvious that not every aspect has the same influence or consequence on indicating the performance level of the system. Many aspects can be summarized under the economics aspect, like security, health, environment and politics. By expressing these aspects in a monetary way it become easier to analyze and decide whether or not an action is profitable. The SHEEP analysis has many connections to the sustainability, which also considers the results of social, ecological and economical aspects. Often these aspects are considered in a FMEA for object functions whereby maintenance activities can be ranked for sustainability (Van Gestel et al. 2004).

The most interesting aspects are the reliability, availability and maintainability of a certain system. These three describe important information on the performance level nowadays (ProRail 2010).

\subsection{Reliability}

To start with the reliability which is directly related to the frequency of failure. The more often a system fails, the lower the reliability. Thus the reliability is the complement of the unreliability. Therefore the relation between the reliability and probability of failure (unreliability) can be expressed by:

$R(x)=1-F(x)$ 
where $R(x)=$ function of reliability; and $F(x)=$ function of cumulative probability of failure.

The reliability is changing over time and therefore also depends on new elements in the system or on maintenance activities/replacements of a certain element. In line with this, the reliability will decrease over time due to usage of the system. This reliability can be calculated, for instance, by using the First Order Reliability Method (FORM). The limit state function will be used as a probabilistic calculation for a failure mechanism model (Steenbergen et al. 2004) like:

$Z=f(x)$

When $Z$ becomes lower than zero the system fails and logically this means if $Z$ is zero or larger that this describes the limit state or non-failure.

\subsection{Availability}

Subsequently, the availability is a theoretical rate of time of which a system is able to fulfill its function. A system can be down due to two causes: unavailability due to planned maintenance or due to failure events (which of course lead to unplanned maintenance). Planned (preventive) maintenance logically leads to a lower probability of failure and thus a smaller chance of unavailability by unplanned (corrective) maintenance. The main task is to find an optimum balance that should lead to the largest possible availability. Thus the availability is the complement of the unavailability. Therefore the relation between the availability and unavailability can be expressed by:

$A=1-U=1-\left(U_{\text {unpl }}+U_{p l}\right)$

where $U_{\text {unpl }}=$ unavailability due to unplanned maintenance; and $U_{p l}=$ unavailability due to planned maintenance.

There is a direct relation between the planned and unplanned unavailability of a system. For example, the planned unavailability (preventive maintenance, inspection, and etc.) may lead to less unavailability due to failure events and vice versa. In other words, a good management of preventive maintenance activities on a system can lead to less interruptions and therefore less unplanned failure causes. This may result in a more controllable and predictable performance level of the system.

\subsection{Maintainability}

At last the maintainability indicates the ease to maintain a system (1) to prevent the system from functional failing (planned unavailability) and (2) the time to repair the system due to functional

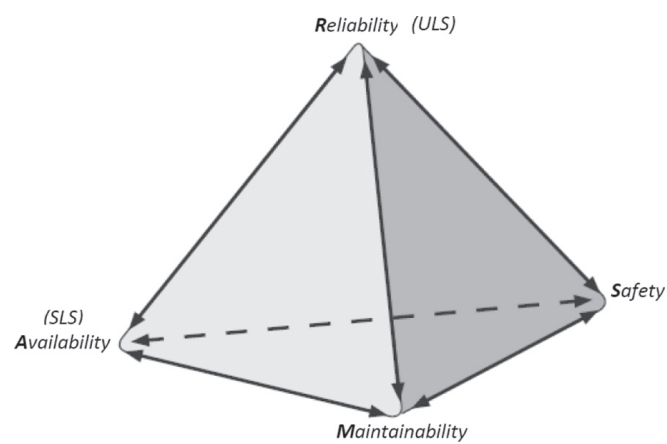

Figure 1. The direct relation and influence on RAMSaspects.

failure of the system (unplanned unavailability). As one can see in the example above that the link between availability and maintainability is very strong and direct. Therefore the maintainability is related to Mean Time To Repair (MTTR) and a good design (adaptions/measures to system may lead to better maintainability).

\section{PROBABILISTIC ANALYSIS}

\subsection{Risks}

A well-known method to quantify risks is by using a probabilistic analysis.

To make an indication of risks its probability of failure and consequences must be determined. The definition of a risk can be seen as the probability of failure of a scenario multiplied by the consequence of that scenario:

$R=P_{f} \cdot C_{f}$

where $P_{f}=$ probability of failure of the system; and $C_{f}=$ economical consequence.

The probability of failure of a system gives the chance of failure due to a failure mechanism or a combination of failure mechanisms.

When the total probability of failure of the system has been calculated, the weak spots can be determined. This gives an indication where and what actions must be taken to decrease this probability of failure. The identification of the weak spots within the system can be determined by comparing the current safety level with the required safety level.

For lowering the risk not only determining the probability of failure is important, but also the consequence of a failure is necessary. The calculation of economic damage will be based on three damage categories: (1) direct material damage; 
(2) direct process damage; and (3) indirect process damage.

\subsection{Optimization}

A tool that can be applied in economic analysis is the Cost-Benefit Analysis (CBA). Costs must be put on a balance against benefits. The costs and benefits contain not only the costs and benefits of the actions that must be taken (financially), but also costs and benefits with respect to nature, environment, spatial quality, and etc. Benefits are mostly defined as the reduction ratio of the probability of annual damage. The optimal safety level in economical way can be achieved by implementation of total costs of actions and the expected damage will thereby be minimalized (Eijgenraam et al. 2000).

The risk-based optimization is adopted as the main principle on which to base an analysis of acceptable risk. The type of optimization has been applied successfully in several earlier studies in engineering. Reference is made to Van Dantzig (1956), Burcharth et al. (1995), Vrijling et al. (1998) and Voortman et al. (1998). The basic form of riskbased optimization is economic optimization that is aimed at minimization of the lifetime cost of the system (see Fig. 2):

$$
\begin{aligned}
C_{\text {life }}(p, X) & =l(p)+R(p, X), \text { with } \\
R(p, X) & =P_{f}(p, X) \cdot C_{f}
\end{aligned}
$$

where $I(p)=$ investment in the system (to decrease the probability of failure); $R(p, X)=$ monetary risk; $P_{f}(p, X)=$ probability of failure of the system; and $C_{f}=$ economical consequence. All these parameters depend on which measure will be taken to lower the lifetime cost ( $p$, vector of design variables and

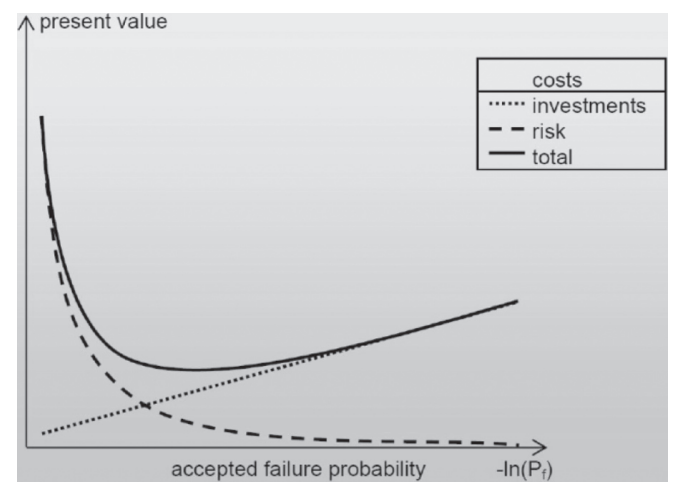

Figure 2. Schematic illustration of optimal safety in an (simplified) economical risk and investment model based on the CBA (Vrijling et al. 2002).
$X$, vector of random variables) and can therefore be used to optimize the variable.

The probability of failure of a system may be evaluated by using system reliability theory, calculating reliability of all components first, followed by an evaluation of the system probability of failure. Extending reliability evaluation with optimization can be done in two ways:

- Top-down approach; and

- Bottom-up approach.

In the top-down approach, lifetime costs of the system are defined in the space of the design variables within the components. Well-known optimization methods may then be used to find the minimum of lifetime costs. In practice, this approach leads to a high-dimensional optimization problem; number of design variables in order of 100 's.

Since the tool is ultimately aimed at supporting decision-making for the definition of acceptable risk levels, it is important that the tool is transparent for decision-makers and design engineers. It is the opinion of many authors that the top-down approach is too much of a black box approach.

An alternative is the bottom-up approach. In this approach lifetime costs are defined in the space of failure probabilities of individual system components. In this case, the number of dimensions of the optimization problem is reduced of the number of individual components in the system. Generally, this means a reduction of the number of dimensions in system optimization by a factor 10 .

To obtain the optimization in this form, the functions of the cost of an individual component have to be found. System reliability theory provides probability as a function of failure probabilities of components and the correlation matrix (Gijsbers 1987). The investment function and the correlation matrix have to be found by a closer analysis of every component (Vrouwenvelder \& Lenos 1987).

The result of the optimization should be independent of the strategy used. It can be proven that the minimum of the lifetime costs can be determined. This is only if the investment function is defined as the minimum investment in the component for a given failure probability. Therefore, the investment function can be found by minimization of the investments in the section for a number of prescribed failure probabilities (Voortman \& Vrijling 2001).

\subsection{Level of economical decision}

The cost-benefit analysis can be calculated on different levels. Mostly, there are three dividing categories: 
- Micro economy (firm);

- Macro economy (nation); and

- Political science.

Each category has its own focus. Starting at the smallest part 'micro economy', a cost-benefit analysis of a firm is relatively simple. The analysis contains an optimization of the process/improvement costs and the gains of the firm. Finally, this should result in maximization of the profit (or minimization of the losses).

The next level 'macro economy' is a bit more complex. The cost-benefit analysis is acting on a higher level of society and this especially relate to the benefits. The cost of a certain activity will be more or less the same, but the benefits of that activity can be low what result in a loss. In macro economy (nation) one may decide to continue this activity when it seems that there are other benefits like growth, employment, currency, inflation, and etcetera. So, the costbenefit analysis has been analyzed on the bigger picture instead of only the activities on the firm.

The highest level 'political science' is based on more immaterial aspects. The costs of a certain activity will however be the same, but benefits can be analyzed by considering more than only activity benefits like environment, culture, health, and etc. These benefits can be classified as intangible. The politicians may decide to accept the losses of a certain activity by considering the intangible aspects worth this loss.

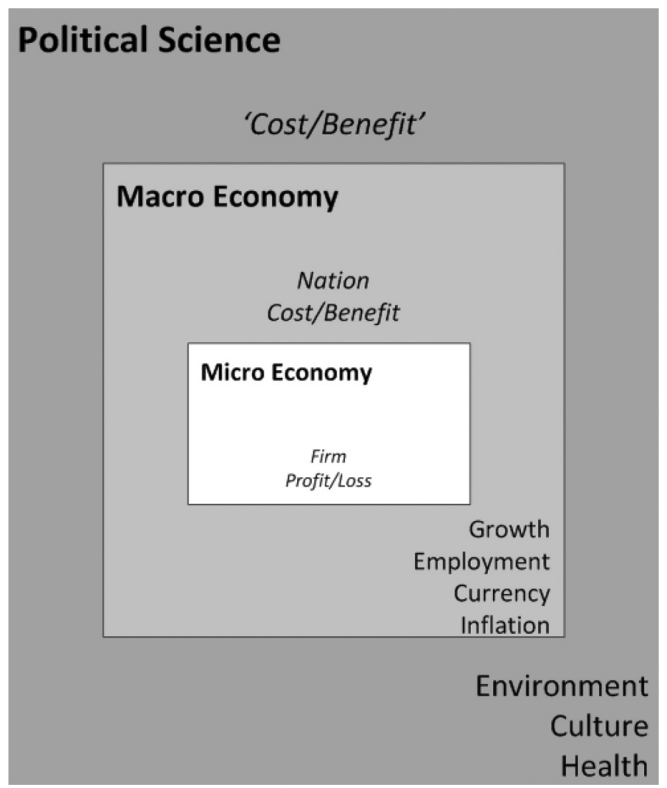

Figure 3. The levels on which economic decisions can be based on.

\section{MAINTENANCE}

\subsection{Deterioration model}

The life span of an object is the time that passes between realization and the failure of the object (loss of function). It may sound logical that strength is often time dependent. The intersection of strength and load determines the moment of failure.

A deterioration model gives the relation between strength and time. The relation can be linear, exponential, logarithmic, and etc. The deterioration model thus determines strength at every point in time and is an approximation of reality. The input required for the model is the initial strength and usually a number of parameters that describe characteristics of the material or the object. The parameters that serve as input for the deterioration model are usually determined from tests or observations. They rarely have a certain value and can usually be best described by a random variable. This means that strength at a certain time is a function of random variables and is thus a random variable itself.

The deterioration models give a stochastic description over the process of strength over time. This describes the objects condition on a certain moment of time. This means that it does not only gives information for determining risks over that period, but also the expected value for the amount of repair on the object. The deterioration model forms therefore an important position in the maintenance planning. However, this piece of information of the behavior of the object is often not known. A mathematical description of the strength process over time has to be found by measurements of the object and by physical research. The model research will be based on a certain time interval what forms the basis for the deterioration model by using curve fitting and extrapolation techniques.

This also introduces model uncertainty. The input parameter in the model will have some uncertainties (numbers based on tests, experiences or intuition). These parameters can therefore be described as stochastic variables with each an own probability density function.

The deterioration process can best be modeled as a stochastic process. The result gives an average value and deviation of the objects strength for each moment of time. The deviation will increase when the uncertainties (in the mathematical model) of the input parameters are larger.

\subsection{Limit state function}

Failure is generally defined as non-performance of what is requested or expected. The limit state is a state, where strength of and load on the 
construction are equal. Two types of limit states can be distinguished, namely:

1. Ultimate Limit State (ULS); and

2. Serviceability Limit State (SLS).

When the ULS is exceeded, failure occurs as result of collapse under extreme loads. Examples of ULS are i.e. collapse of an earth body, deflection of the structure, and etc. When the SLS is exceeded, the functional demands can no longer be met (for a certain moment of time). Deflections of a floor, cracking in reinforced concrete, waves which are too high behind a breakwater and so on, are examples of exceeding of SLS. It must be named that there is a significant difference in limit states between design period and maintenance period of objects in risk management. Often this difference is forgotten or used interchangeably.

Generally, failure can be schematized as exceeding the load over the strength. The state of an object can be described using a limit state function:

$Z=R-S$

where $R=$ strength; and $S=$ load.

If the strength and/or the load are described with random variables, $Z$ is also a random variable. If $Z<0$ the object fails. The probability of failure can be calculated by the area of the joint probability density function whereby $Z<0$. By using equation 6 the probability of failure can be given by:

$\operatorname{Pr}\{Z<0\}=\int_{-\infty}^{0} f_{z}(\xi) d \xi$

where $f_{z}(\xi)=$ probability density of $Z$; and $\xi=$ realization of $Z$.

The difficulty with the determination of the failure probability is the fact that the distribution function of $Z$ usually cannot be determined exactly. Only in a few cases, i.e. where all variables have a known distribution, the distribution of $Z$ can be determined.

\subsection{Maintenance strategies}

Maintenance activities have certain goals that must be fulfilled. But one must first define the real function of maintenance within the system. The core of maintenance has always been based on technical and economic aspects. Eventually a balance between technical and economic aspects make a good maintenance plan. Many companies do have a profit-driven maintenance plan, which describes a desire to make as high profit as possible. Other strategies with maintenance plans are availability-driven, reliability-driven, comfort-driven, and etc. First of all, it is proper to define the term maintenance in just one sentence (Vrijling \& Van Gelder 2006): "All activities aimed at retaining a structure's technical state or at reverting it back to this state, which is considered a necessary condition for the structure to carry out its function".

These activities include both the repair of the structural strength, back to its original strength, and executing inspections. The costs of maintenance of civil engineering objects amounts to approximately $1 \%$ of the founding costs per year. For a life span around 100 years this means that the maintenance costs are of the same magnitude as the construction costs. The decline in i.e. new housing development projects, maintenance costs are clearly becoming an increasingly greater share of the expenses.

A direct consequence is the desire to minimize maintenance costs. In order to realize this, the optimal maintenance strategy has to be found. From the mechanical engineering maintenance theory, the following classifications in strategies are known (Vrijling \& Van Gelder 2006):

1. Corrective maintenance (failure dependent maintenance); or

2. Preventive maintenance (state dependent maintenance).

In the first case of fault dependent maintenance, an object is repaired or replaced when it can no longer fulfill its function. Thus, repair takes place after failure; therefore a failure intervention is involved. The life of an object is fully exploited. Objects failure (and the associated costs) is accepted. In engineering this type of maintenance is usually not acceptable, because generally the accepted probability of failure is limited. This type of maintenance can, however, be applied to non-integral construction parts (parts which do not contribute to the stability of the entire object), with modest consequences of failure (provided reparation or replacement is not postponed for too long).

In the second case with condition dependent maintenance the state of the object is determined at set intervals, by means of inspections. The decision whether to carry out repairs is based on observations. The inspection intervals can be regular or dependent on the condition of the object. In the latter case condition parameters, indicating the condition of the object, have to be visible. The probability of failure in a period between two inspections has to be sufficiently small. Generally, the lifetime of the object can be better exploited than with usage dependent maintenance, but the costs of the inspections do have to be taken into account (Ten Wolde \& Ghobbar 2012). 


\subsection{Net Present Value (NPV)}

The maintenance costs depend on the decrease of strength and can therefore be seen as a function of the amount of maintenance:

$C_{M}=g(\underline{\Delta R}(t))$

where $g(\underline{\Delta R}(t))=$ maintenance costs function dependent on change in strength over time.

When costs will be calculated over a certain time line, one is able to assess and compare this outcome with maintenance activities. The Net Present Value (NPV) of the costs due to failure has been calculated for a situation in which this risk annually occurs and will be discounted to the current situation. This can be calculated by using equation 8 :

$C_{N P V}(t)=\frac{C_{M}}{(1+r)^{t}}$

where $C_{M}=$ maintenance costs; $r=$ annual discount rate; and $t=$ time.

The annual discount rate of $2.5 \%$ is applicable whereby the inflation has not been taken into account. Eventually this NPV can be implemented, by using equation 9 , in the expected net present value of the maintenance costs (investment) over its lifetime and the representing risk, by using equation 4 , at that moment of time:

$$
\begin{aligned}
& E[N P V]_{I}(\Delta I)=\sum_{n=1}^{N} \frac{C_{I}}{(1+r)^{n \cdot \Delta I}} \\
& E[N P V]_{R}(t)=\sum_{t=1}^{T} \frac{P_{f}(t) \cdot C_{f}}{(1+r)^{t}}
\end{aligned}
$$

where $C_{I}=$ investment costs; $r=$ annual discount rate; $n=$ total amount of maintenance activities; $\Delta I=$ maintenance interval; $P_{f}(t)=$ probability of failure; $C_{f}=$ economical consequence; and $t=$ time.

Hereby $P_{f}$ is the annual probability of failure, which is based on the limit state function $Z$ (see also equation 7). These formulas can be used to determine the most (economically) optimal maintenance interval over time. When the expected investment costs (equation 10) summed with the expected risk after these investment (equation 11) are lower than the current risk, it is profitable to take these investment measures. Otherwise, it helps to decide not to take any investments. Hereby a certain optimum can be determined (see Fig. 4).

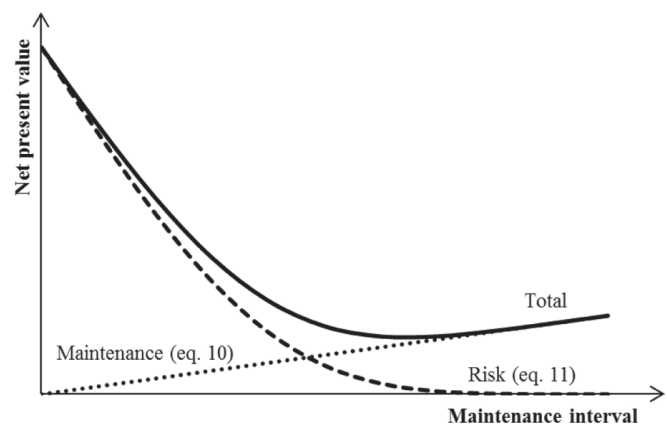

Figure 4. The net present value of the (maintenance, risk and total) costs dependent on the maintenance time interval (Vrijling \& Van Gelder 2006).

The optimization of maintenance can be determined by searching for the minimum of the expected net present value of the total costs. This paper will only focus on the invariable deterioration process whereby the maintenance intervals are of the same length. The expected net present value of the total costs depend of just one single variable; the maintenance interval:

$E[N P V](t)=f(t)$

The function in equation 12 has a minimum for a certain value of $t$ in which:

$f^{\prime}(t)=0$ and $f^{\prime \prime}(t)>0$

For example, maintenance on a road will describe an invariable deterioration process whereby all the parameters stay constant and only the maintenance interval is variable. The expected net present value will result in a constant maintenance interval. However, this is only true when the reconditioning will be done with the same properties as the original condition.

\section{CASE STUDY}

This section shows the basic probability theory in combination with the risk-driven RAMSSHEEP analysis applied on 'The Afsluitdijk', a primary flood defense system in The Netherlands.

The gathered data for probability of flooding has been based on annual maximum water levels on 81 years from 1932 until now. Other supporting data has been based on research and case studies that was supported by RWS. All data assumptions that have been made are approved by RWS and will therefore be credible and reliable enough to use in this case study. 


\subsection{Background}

The Dutch Deltacommittee advised the Dutch government on controlling the probability of flooding of the primary flood defence systems to an economic and social optimum. This advice has been based on the climate change what inter alia will lead to water level rise (Deltacommissie 2008).

One of the advices was that the dikes in the IJsselmeer area should be increased to fulfill the requirements in case of chance in failure. The Afsluitdijk should also be accounted for to increase its crest level.

In this case study the complete system of the Afsluitdijk has been analyzed and can be decomposed by: dike, road, navigation lock, drainage sluice. Hereby, the focus will lay on the economical optimum based on risk analysis. As the Deltacommittee advised, this case study will give an optimum solution for investing in the system and also how and when it should be maintained.

\subsection{Illustrated example}

A risk-driven RAMSSHEEP analysis on the primary flood defense system 'The Afsluitdijk' must be applied on the complete system, what includes all its object functions:

1. Retaining of water (high/storm level);

2. Discharging of surplus water from the rivers;

3. Navigating ships through locks; and

4. Road connection over the dike.

First of all, by making an economical probabilistic analysis of the current situation with the risk formula (equation 4) one is able to analyze which function is dominantly present in the determination the total risk of the system.

Figure 5 and Table 1 represent the present value of the monetary risk and points out that the dike caries the largest risk as a part of the total.

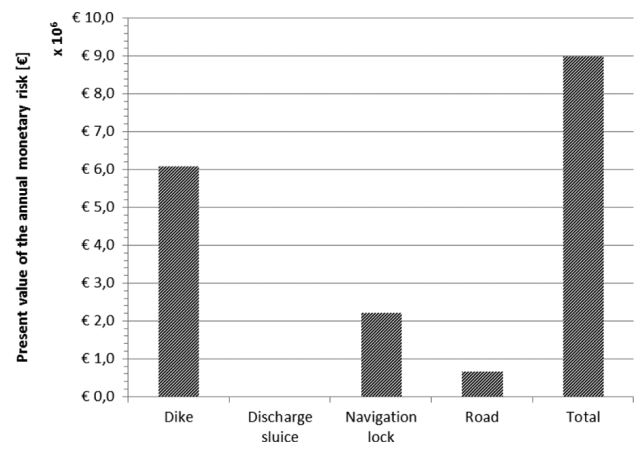

Figure 5. Schematically view of the contribution of the object functions to the total present value of the monetary risk within the system.
Table 1. Overview of the division of functional risk.

\begin{tabular}{lrr}
\hline Element/object & $\begin{array}{l}\text { Annual monetary } \\
\text { risk }\end{array}$ & $\begin{array}{l}\text { Part of } \\
\text { total }\end{array}$ \\
\hline Dike & $€ 6,087,000$ & $67.8 \%$ \\
Discharge sluice & $€ 20,000$ & $0.2 \%$ \\
Navigation lock & $€ 2,214,300$ & $24.7 \%$ \\
Road & $€ 657,000$ & $7.3 \%$ \\
Total & $€ 8,978,300$ & $100.0 \%$ \\
\hline
\end{tabular}

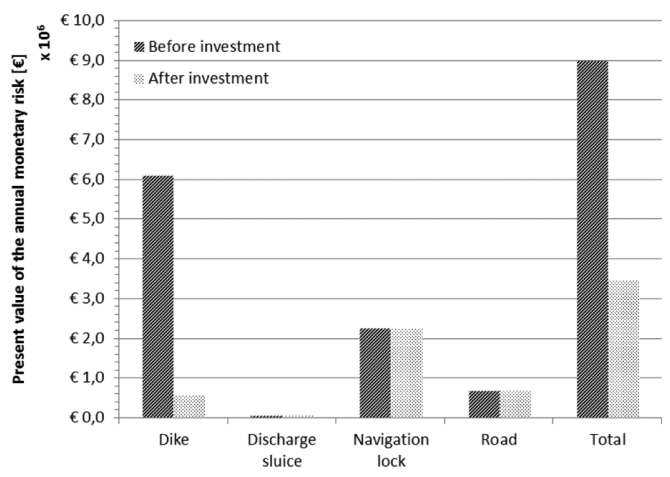

Figure 6. Schematically view of the contribution of the object functions to total net present value of the monetary after taking investments.

The risks determined in Table 5, should be reduced in the most efficient and economical way. In other words, some measurements should be taken to reduce the probability of occurrence of a certain failure. These investments in the system can be modeled on several parameters, like an extra road lane, higher crest of the dike, and etc. On every investment measurement a cost-benefit analysis will be made, to receive more insight in the influence of the probability of occurrence on the most efficient measure, based on equation 5.

Figure 6 and Table 2 represent the present value of the monetary risk and points out that the dike does no longer carry the largest risk, due to the investment (increasing dike crest) (Kuijper 1992). The result of the calculation showed that investment for the discharge sluice, navigation lock and road was not profitable in comparison with its current risk; so no investment was suggested.

The current situation makes it clear that the dike had the highest monetary risk and was dominant in the analysis. After the investment analysis has been made, the choice of executing this investment based on the economical most beneficial value changed this dominancy. If an investment has been made, the expected costs should be decreased. 
Table 2. Investments that lead to lower expected costs given by the present value.

\begin{tabular}{lrrr}
\hline & \multicolumn{2}{c}{ Annual monetary risk } & \\
\cline { 2 - 3 } & \multicolumn{1}{l}{$\begin{array}{l}\text { Before } \\
\text { investment }\end{array}$} & $\begin{array}{l}\text { After } \\
\text { investment }\end{array}$ & \multicolumn{1}{l}{$\begin{array}{l}\text { Part of } \\
\text { total }\end{array}$} \\
\hline Dike & $€ 6,087,000$ & $€ 557,207$ & $16.2 \%$ \\
Discharge sluice & $€ 20,000$ & $€ 20,000$ & $0.5 \%$ \\
Navigation lock & $€ 2,214,300$ & $€ 2,214,300$ & $64.2 \%$ \\
Road & $€ 657,000$ & $€ 657,000$ & $19.1 \%$ \\
Total & $€ 8,978,300$ & $€ 3,448,507$ & $100.0 \%$ \\
\hline
\end{tabular}

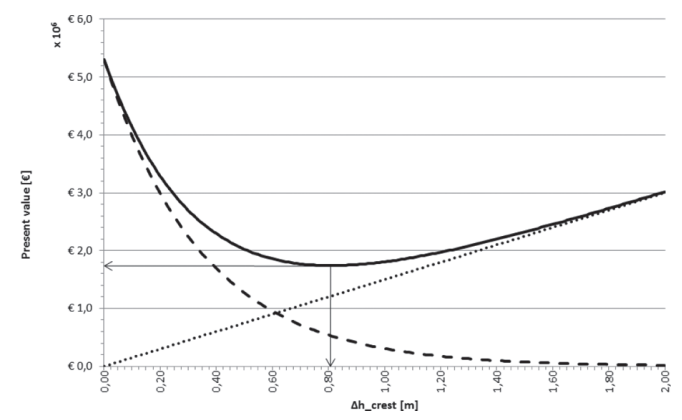

Figure 7. Optimization of the crest height of the dike.

In Figure 7 the risk optimization of the height of the dike crest has been shown. The dashed line represents the decrease of the risk for a higher crest level that comes together with a higher investment cost (dotted line). According to equation 5 (the superposition of the dashed and dotted line) the economical most beneficial crest height can be determined.

Now when the monetary risk has been put to a minimum it is also necessary to conserve the systems' quality for the coming years based on the principle of LCC. This analysis led to a predictive maintenance interval for as well as the navigation lock and the road of respectively 14 and 18 years. In this specific case the discharge sluice and dike will not give any results, due to very slow deterioration.

The analysis for the maintenance intervals has been calculated with equations 9,10 and 11 based on the minimum costs over its lifetime that has been given in equation 13 .

The results from this analysis can also be used to calculate the optimal reliability and availability what one may use to control the system (threshold level) and to steer on. The reliability and availability have been given according to the equations 1 and 3. N.B. The practical approach for calculating the reliability strongly depends on the amount and quality of available historical data. This is crucial for an accurate reliability number.

The availability can be calculated by using the reliability, maintenance interval and MTTR. When these parameters have been implemented in equation 3 the availability is known:

$$
\begin{aligned}
A & =1-U=1-\left(U_{\text {unpl }}+U_{p l}\right) \\
& =1-\left(\frac{1}{R} \cdot \frac{M T T R_{c}}{\Delta I_{M}}+\left(1-\frac{1}{R}\right) \cdot \frac{M T T R_{p}}{\Delta I_{M}}\right)
\end{aligned}
$$

where $R=$ reliability; $M T T R_{c}=$ corrective mean time to repair; $M T T R_{p}=$ preventive mean time to repair; and $\Delta I_{M}=$ maintenance interval.

It is not remarkable that the reliability and availability of the dike are higher than the other object functions (see results of Table 4). This is due to the fact that the failure damage of this function is extremely higher.

The fact that the dike does not need any regular maintenance in this case, this has been indicated in Table 3 by preventive MTTR, depends on the initial situation, but in general the maintenance intervals increase because the subsoil becomes stiffer

Table 3. An overview of the preventive and corrective

\begin{tabular}{|c|c|c|c|}
\hline \multirow[b]{2}{*}{ Function } & \multicolumn{2}{|l|}{ MTTR [d] } & \multirow[b]{2}{*}{ Maintenance } \\
\hline & Preventive & Corrective & \\
\hline Dike & 0 & 182 & $\begin{array}{l}\text { Heightening } \\
\text { crest level }\end{array}$ \\
\hline $\begin{array}{l}\text { Discharge } \\
\text { sluice }\end{array}$ & - & - & $\begin{array}{l}\text { Repairing bec } \\
\text { protection }\end{array}$ \\
\hline $\begin{array}{l}\text { Navigation } \\
\text { lock }\end{array}$ & 30 & 365 & $\begin{array}{l}\text { Vertical } \\
\text { cut-off wall }\end{array}$ \\
\hline Road & 128 & 182 & $\begin{array}{l}\text { Renewing } \\
\text { asphalt }\end{array}$ \\
\hline
\end{tabular}
MTTR in days to calculate the availability per function.

Table 4. An overview of the reliability and availability numbers and the corresponding maintenance interval

\begin{tabular}{|c|c|c|c|c|}
\hline Function & $\begin{array}{l}\mathrm{R} \\
{[\mathrm{RP} \text { in } \mathrm{yr}]}\end{array}$ & $\begin{array}{l}\mathrm{A} \\
{[\%]}\end{array}$ & $\begin{array}{l}\Delta \mathrm{I}_{\mathrm{M}} \\
{[\mathrm{yr}]}\end{array}$ & Maintenance \\
\hline Dike & 20,900 & 99.9 & - & $\begin{array}{l}\text { Heightening } \\
\text { crest level }\end{array}$ \\
\hline $\begin{array}{l}\text { Discharge } \\
\text { sluice }\end{array}$ & 1000 & 99.9 & - & $\begin{array}{l}\text { Repairing bed } \\
\text { protection }\end{array}$ \\
\hline $\begin{array}{l}\text { Navigation } \\
\text { lock }\end{array}$ & 86 & 98.5 & 14 & $\begin{array}{l}\text { Vertical } \\
\text { cut-off wall }\end{array}$ \\
\hline Road & 80 & 97.6 & 18 & $\begin{array}{l}\text { Renewing } \\
\text { asphalt }\end{array}$ \\
\hline
\end{tabular}
and activity. 


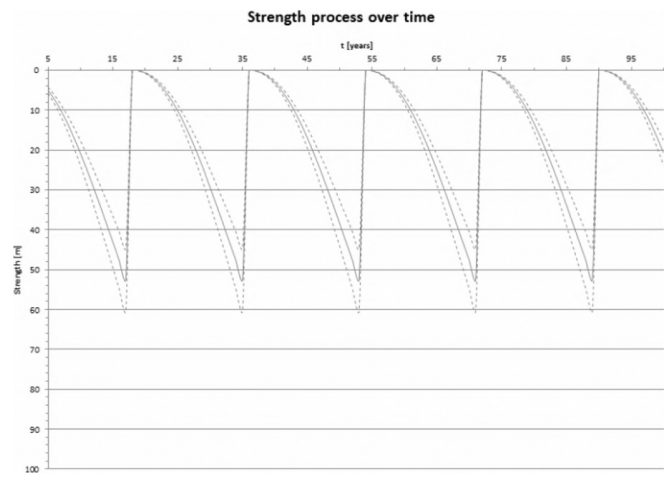

Figure 8. The process of the strength of the road over time, indicated by the length of cracks in meters (Z-function).

over time. The variable deterioration process of the dike, of course, can explain this (Kuijper 1992).

Instead of the dike, the other object functions describe an invariable deterioration process and therefore show a constant maintenance interval over its life cycle; as we can see in Figure 8 the maintenance interval of the road is 18 years.

\section{CONCLUSION}

This research paper answers the original research question, by doing a theoretical research and enriching this with an elaborated example. The research question was to assess (advantages and disadvantages) whether RAMSSHEEP can be applied as a risk-driven maintenance tool by applying a probabilistic approach with LCC. The illustrated example shows how to apply a risk-driven RAMSSHEEP analysis based on a probabilistic approach with an economical driver to optimize. This resulted in investment activities on the current situation and an optimal maintenance strategy.

The RAMSSHEEP analysis is applicable to any possible system within the infrastructural sector. This analysis determines the optimal maintenance interval based on failure frequency and costs by using historical data. Not only RWS will benefit from this probabilistic approach, but also users in general could benefit due to a good balance of tax money and safety (maintenance).

The RAMSSHEEP analysis is applied to a Dutch primary flood defense system. Several assumptions have been made in strength deterioration (failure frequency) and investment costs to model the system. According to the results of the analysis, the costs are minimized when:

- The crest level of the dike will be increased by $0.81 \mathrm{~m}$;
- The asphalt layer will be renewed every 18 years; and

- The bed protection in front of the navigation lock will be repaired every 14 years.

These maintenance activities describe a maintenance strategy that does not imply any (unforeseen) calamities. The annual savings, based on risks, will be more than $€ 5.5$ million (of almost $€ 9.0$ million) at the systems optimum for the Afsluitdijk.

The risk-driven RAMSSHEEP approach is mainly based on the economical driver to optimize the reliability, availability and maintenance intervals, so knowing this the type of analysis can best be renamed as EMAR: Economics, Maintenance, Availability and Reliability. This risk-driven type of analysis gives a broader, more simple and complete basis for solving an infrastructural problem. It should be noted that an EMAR analysis should be applied per object function within a system (decomposition and interfaces) and not per system function. All the object functions together (integration) will give a result for the EMAR analysis on top level (system level).

\section{REFERENCES}

Andrews, J.D. \& Moss, T.R. 2002. Reliability and Risk Assessment. London and Bury St. Edmunds: Professional Engineering Publishing Limited.

Burcharth, H.F., Dalsgaard Sørensen, J. \& Christiani, E. 1995. Application of reliability analysis for optimal design of vertical wall breakwaters. Proceedings of the International Conference on Coastal and Port Engineering in Developing Countries (COPEDEC).

Deltacommissie 2008. Samen werken met water: Een land dat leeft, bouwt aan zijn toekomst: Bevindingen van de Deltacommissie 2008. Den Haag: Hollandia Printing.

Eijgenraam, C.J.J., Koopmans, C.C., Tang, P.J.G. \& Verster, A.C.P. 2000. Leidraad voor kosten-baten analyse - onderzoeks-programma Economisch Effecten Infrastructuur. Den Haag: Ministerie van Verkeer en Waterstaat \& Ministerie van Economische Zaken.

Gijsbers, F.B.J. 1987. Optimisation of Maintenance TNO-IBBC report B-86-549. Delft: TNO.

Kuijper, H.K.T. 1992. Maintenance in Hydraulic Engineering, Economically Sound Planning of Maintenance. Delft: Delft University of Technology.

Moubray, J.M. 1999. Reliability-centred Maintenance. Oxford: Elsevier Ltd.

Nowlan, F.S. \& Heap, H.F. 1978. Reliability-Centered Maintenance. Washington, DC: United States Department of Defense (Manpower, Reserve Affairs and Logistics).

ProRail 2010. Hand-out RAMS/LCC analyse: Leidraad voor Systems Engineering. NL: Prorail.

Rijkswaterstaat 2012. Leidraad RAMS-sturen op prestaties van systemen. Den Haag: Ministerie van Verkeer en Waterstaat. 
Steenbergen, H.M.G.M., Lassing, B.L., Vrouwenvelder, A.C.W.M. \& Waarts, P.H. 2004. Reliability analysis of flood defence systems. HERON Volume 49 No. 1: 51-73.

Ten Wolde, M. \& Ghobbar, A.A. 2012. Optimizing Inspection Intervals. Reliability Engineering \& System Safety Volume 114 June 2013: 137-147.

Van Dantzig, D. 1956. Economical decision problems for flood prevention. Econometrica No. 24: 276-287.

Van den Breemer, J.J.A., Al-Jibouri, S.H.S., Veenvliet, K.T. \& Heijmans, H.W.N. 2009. RAMS and LCC in the design process of infrastructural construction projects: an implementation case. Enschede: Twente University of Technology.

Van Gestel, P., Bouwman, E. \& Reijnen, I. 2004. FMECA Failure Mode Effect and Criticality Analysis. Deventer: Sigma, Wolters Kluwer.

Voortman, H.G, Kuijper, H.K.T, Vrijling, J.K 1998. Economic optimal design of vertical Breakwaters. Proceedings 26th International Conference on Coastal Engineering (ICCE): 2124-2137.
Voortman, H.G. \& Vrijling, J.K. 2001. A Risk-based optimization strategy for large-scale flood defence systems. Delft: Delft University of Technology.

Vrijling, J.K. \& Van Gelder, P.H.A.J.M. 2006. Probabilistic Design in Hydraulic Engineering. Delft: Delft University of Technology.

Vrijling, J.K., Van Gelder, P.H.A.J.M., de Ridder, H.A.J., Kuijper, H.K.T., \& Vrouwenvelder, A.C.W.M. 2002. Probability in Civil Engineering. Delft: Delft University of Technology.

Vrouwenvelder, A.C.W.M. \& Lenos, S. 1987. Optimisation of Maintenance-part II TNO-IBBC report B-87-717. Delft: TNO.

Zaal, T.M.E. 2011. Profit-Driven Maintenance for Physical Assets. Geldermalsen: Maj Engineering Publishing. 